\title{
Pharyngeal pituitary non-functioning adenoma with normal intra-sellar gland: massive tumor shrinkage on octreotide therapy
}

Nathalie Pugnale, François Waridel ${ }^{1}$, Hanifa Bouzourène ${ }^{2}$, Ariane Boubaker ${ }^{3}$, Mauro Pugnale ${ }^{4}$ Rolf C Gaillard and Fulgencio Gomez

Division of Endocrinology, Diabetology and Metabolism, Department of Internal Medicine, ${ }^{1}$ Service of Oto-rhino-laryngology, ${ }^{2}$ Institute of Pathology, ${ }^{3}$ Service of Nuclear Medicine, ${ }^{4}$ Service of Diagnostic and Interventional Radiology, University Hospital and Lausanne Medical School, CHUV, 1011 Lausanne, Switzerland

(Correspondence should be addressed to F Gomez, Division of Endocrinology, Diabetology and Metabolism, Department of Internal Medicine, BH 10, Centre Hospitalier Universitaire Vaudois (CHUV), 1011 Lausanne, Switzerland; Email: Fulgencio.Gomez@chuv.hospvd.ch)

\begin{abstract}
Objective: Functioning or non-functioning ectopic tumors may develop from pharyngeal pituitary remnants. They constitute $<1 \%$ of all obstructive pharyngeal masses and they have a strong tendency to bleed. We report a case of a non-functioning ectopic pituitary adenoma of the rhino-pharynx studied over a long-term somatostatin analog treatment.

Patient and treatment: A 60-year-old woman presented with severe posterior epistaxis. She had complained of nasal obstruction for the past 2 years. Magnetic resonance imaging (MRI) and endoscopic examination revealed a $2 \mathrm{~cm}$ exophytic, bleeding mass in the cavum, which was judged inoperable, and a biopsy was performed. On immunostaining, tumor cells were positive for pancytokeratins MNF 116 and C11, epithelial membrane antigen, chromogranin and neuron-specific enolase (NSE), and negative for synaptophysin, desmin, actin, estrogen and progesterone receptors, all anterior pituitary hormones and human chorionic gonadotropin. Blood levels of the above hormones and tumor markers were normal, except for a moderate elevation of NSE $(33.8 \mu \mathrm{g} / \mathrm{l}$, normal value $<12 \mu \mathrm{g} / \mathrm{l}$ ). It was concluded that this was a non-functioning pituitary adenoma of the rhino-pharynx. MRI showed a normal intra-sellar pituitary gland, including the normal bright signal of the posterior lobe. Somatostatin receptor scintigraphy (SRS) disclosed intense tracer uptake in the tumor, indicating high somatostatin receptor content. There was also an intense uptake in the intra-sellar pituitary. Therapy with long-acting octreotide was started, $20 \mathrm{mg}$ per month i.m.

Results: The patient has been on octreotide for the last 12 months. Nasal obstruction rapidly subsided and bleeding did not recur. Repeated endoscopic examinations showed rapid tumor reduction, the mass shrinkage being almost complete at 3 months. This was confirmed by MRI, while SRS showed markedly decreased uptake in the residual tumor and the intra-sellar pituitary, and NSE became normal.

Conclusion: Pharyngeal pituitary remnant adenomas are rare, but they must be considered in the differential diagnosis of bleeding or obstructive masses of the rhino-pharynx. In this case, the positive SRS influenced the choice of octreotide, as an alternative to surgery. As we show for the first time in this location, octreotide can exert prolonged and marked anti-tumoral effects in non-functioning adenoma.
\end{abstract}

European Journal of Endocrinology 148 357-364

\section{Introduction}

Ectopic pituitary tumors are a rare cause of pharyngeal obstructive or bleeding masses, but remnants of the Rathke pouch can be found along the cranio-pharyngeal migration route towards the sellar area in practically every individual, when carefully sought $(1,2)$. However, their function remains unknown (1, 4-6). Tumors developing from those remnants are usually referred to as ectopic pituitary tumors. Since the first description by Erdheim (3) there have been about 74 reported cases. Their localization and type of secretions are summarized in Table 1. They are found most often in the sphenoidal sinus and the supra-sellar region and less frequently in the rhino-pharynx with only a few cases reported in this localization. Non-functioning and adrenocorticotropin (ACTH)-secreting tumors are the most frequent types.

Therapy of those masses has been in general surgical, often followed by external radiotherapy. There have been 
Table 1 Localization and secretion in 74 cases of ectopic pituitary adenoma.

\begin{tabular}{|c|c|c|c|c|c|c|c|c|c|c|c|}
\hline & NSE & GH & LH & FSH & ACTH & PRL & ACTH and TSH & GH and PRL & TSH & CP & References \\
\hline Total (74) & 24 & 5 & 1 & 3 & 17 & 15 & 3 & 1 & 1 & 4 & - \\
\hline Sphenoidal sinus & 6 & 2 & - & - & 5 & 6 & 2 & 1 & 1 & 1 & $17-30$ \\
\hline Suprasellar & 4 & 2 & - & - & 5 & 2 & 1 & - & - & - & $31-45$ \\
\hline Nasopharynx & 3 & - & - & 2 & - & - & - & - & - & - & $46-49$ \\
\hline Cavernous sinus & 2 & - & - & - & 3 & 2 & - & - & - & - & $57,58,61,62$ \\
\hline Clivus & 3 & - & - & - & 1 & 3 & - & - & - & - & 59,60 \\
\hline Third ventricle & 2 & - & 1 & 1 & - & - & - & - & - & 1 & 55,56 \\
\hline Pituitary stalk & 2 & - & - & - & 2 & - & - & - & - & - & 50 \\
\hline Pharynx & 2 & 1 & - & - & 1 & 2 & - & - & - & 2 & $51-54$ \\
\hline
\end{tabular}

$\mathrm{CP}=$ craniopharyngioma (references $63-66) ; \mathrm{FSH}=$ follicle-stimulating hormone.

attempts at treatment of ectopic pharyngeal pituitary with dopamine agonists, which succeeded in lowering hormone secretion $(7,8)$, but to the best of our knowledge there has been no attempt at medical therapy with somatostatin analogs. It must be stressed that the endocrine nature of these tumors is usually recognized after immunohistochemical study of the excised tissue, and that hormonal secretion into blood has seldom been assessed. We report here the first case of a pharyngeal pituitary tumor which is being successfully treated with a long-acting preparation of octreotide.

\section{Case report}

A 60-year-old woman presented with a first episode of intense posterior nasal bleeding lasting for several days and requiring emergency care. During the previous 2 years she had noticed progressive nasal obstruction. There was no headache or other local symptoms. She was on metformin for type 2 diabetes and on an angiotensin-converting enzyme inhibitor for mild hypertension, both well controlled, and on no other drugs. Posterior rhinoscopy followed by panendoscopy using a rigid adult bronchoscope showed a fungating, hard mass easily bleeding on contact, which was judged inoperable, and a biopsy was performed. The patient presented no endocrine abnormalities and was not receiving estrogen replacement therapy. Posterior nasal bleeding subsided after several hours. After the histological diagnosis was carried out, a long-acting preparation of octreotide (Sandostatin LAR; Novartis, Basle, Switzerland) was administered at a dose of $20 \mathrm{mg}$ i.m. every 4 weeks.

\section{Materials and methods}

MRI was performed by using a 1.5 T MR unit (Magnetom Symphony; Siemens Medical System, Iselin, NJ, USA) with a quadrature head coil. The following MRI imaging sequences were used: T1 sagittal, transverse, T2 fatsat transverse, three-plane spin echo fatsat T1-weighted after gadolinium injection. Somatostatin receptor scintigraphy (SRS) was performed after injection of $190 \mathrm{MBq}{ }^{111}$ In-DTPA-D-Phe-1-octreotide (OctreoScan; Mallinckrodt Medical, Petten, The Netherlands). Whole-body scans, planar images (500000 counts, matrix $256 \times 256$ ) and single photon emission computed tomography (SPECT, matrix $128 \times 128$, zoom $1.2,360^{\circ}, 120$ projections, $45 \mathrm{~s}$ per frame) of the head were obtained 3 and $24 \mathrm{~h}$ after injection using $20 \%$ windows centered over both ${ }^{111}$ In energy peaks (172 and $245 \mathrm{keV}$ ). SPECT images were reconstructed with a Butterworth filter (cut-off 0.7, order 5.0) and transverse, coronal and sagittal sections were used for final diagnosis.

The biopsy specimens obtained during panendoscopy were fixed in $10 \%$ buffered formalin, embedded in paraffin, and stained with hematoxylin and eosin (H\&E), periodic acid-Schiff, and Alcian blue at $\mathrm{pH} 2.5$. Immunohistochemical staining was performed. To this end, $5 \mu \mathrm{m}$ paraffin sections were rehydrated and subjected to microwave treatment for antigen retrieval. The peroxidase anti-peroxidase technique was chosen as the detection system. The antigens tested were the following (dilution and origin of antibodies in brackets) - two cytokeratins, MNF 116 (1:200, Dako, Zug, Switzerland) and C11 (1:10, Novocastra, Nunningen, Switzerland), epithelial membrane antigen (EMA), a marker of eccrine differentiation (1:100, Dako), gross cystic disease fluid protein 15, a marker of eccrine differentiation (1:250, University Hospital and Lausanne Medical School), $\alpha-2$ ZN-glycoprotein (1:500, Nordic, Tilburg, Holland), S100 protein (1:2000, Dako), nonspecific enolase (NSE) (1:900, Dako), glial fibrillary acidic protein (1:100, Dako), chromogranin A and B (1:100, Dako), synaptophysin (1:25, Dako), CD 34 (1:80, Immunotech, Nyon, Switzerland), desmin (1:40, Dako), actin (not diluted, Enzodiagnostics, Dossenheim, Germany), estrogen receptors (1:20, Dako), progesterone receptors (1:100, Dako), thyrotropin (TSH) (1:3000, Dako), growth hormone $(\mathrm{GH})$ (1:2000, Dako), luteinizing hormone (LH) (1:3000, Dako), human chorionic gonadotropin (1:1500, Dako), ACTH (1:2000, Dako) and prolactin (PRL) (1:2500, Dako). 


\section{Results}

During the initial evaluation, rhinoscopic examination showed an exophytic hard mass in the left cavum necessitating a pandoscopy for a sufficient biopsy specimen. MRI showed a $2 \mathrm{~cm}$ spherical mass, located in the left part of the cavum, homogeneous and displaying marked contrast enhancement (Fig. 1A and B). Intrasellar anterior and posterior pituitary lobes were normal, and there was no apparent anatomical connection between the sellar content and the pharyngeal mass. The endoscopic and MRI picture were consistent with a primary epithelial rhino-pharynx cancer. The first SRS performed at diagnosis showed an uptake of the tracer by the tumor on the SPECT images performed at $3 \mathrm{~h}$, which increased and became intense $24 \mathrm{~h}$ after injection (Fig. 2A-C). We observed a similar uptake of the tracer by the normal pituitary. Whole-body scan and planar images revealed a physiological tracer distribution.

At histological examination, the growth pattern of the tumor was trabecular with sheets and cords separated by fibrous stroma. Tumor cells were round or
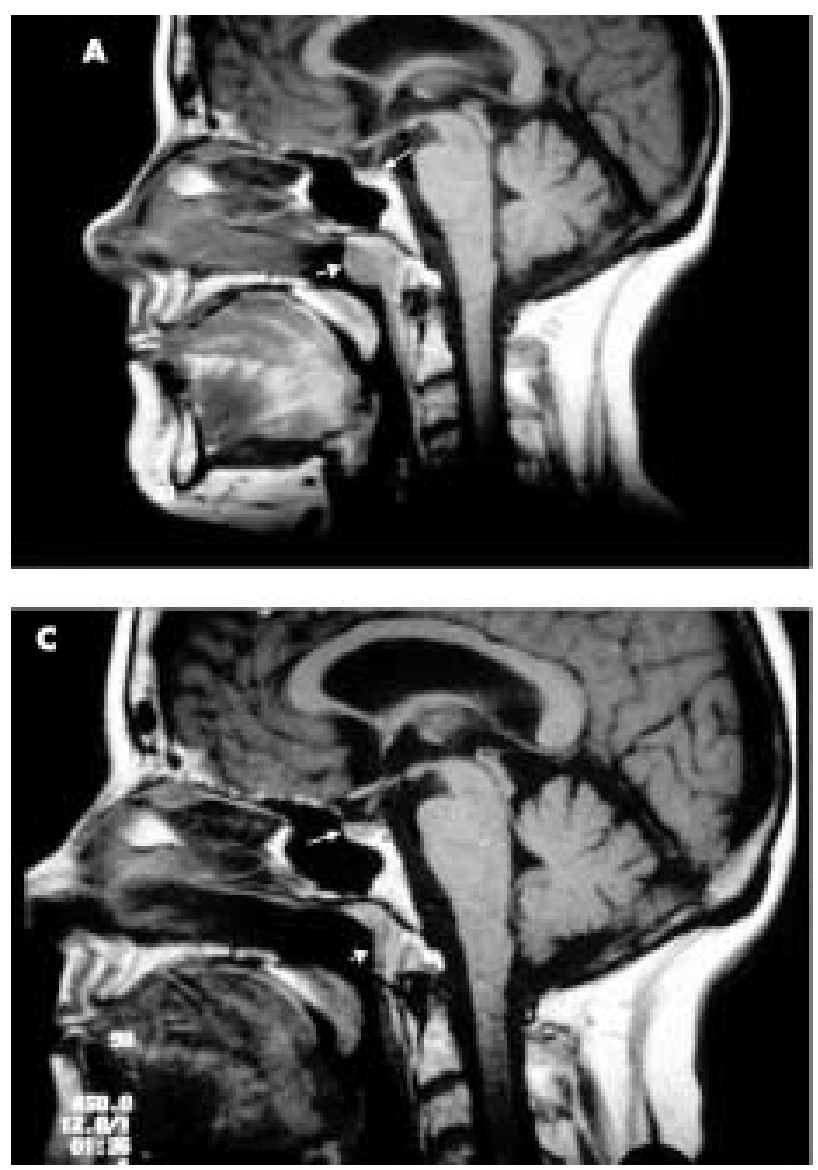

Figure $1 \mathrm{MRI}$ appearance of the mass in the rhino-pharynx (shorter arrows) and of the intra-sellar pituitary (longer arrows). (A and B) before $(C$ and $D)$ after a 3 month long-acting octreotide treatment. Note the normal appearance of the anterior pituitary and the normal bright spot of the posterior pituitary lobe on native scans $(A$ and $C$ ), the marked gadolinium enhancement of intra-sellar pituitary and of the rhino-pharynx mass $(B$ and $D)$, and the striking mass shrinkage on therapy $(C$ and $D)$. polygonal and had round or oval nuclei and variable amounts of acidophilic cytoplasm. Nucleocytoplasmic atypia and mitoses were absent (Fig. 3A and B). There was no mucin secretion by the tumor cells. Tumor cells were diffusely positive for cytokeratin MNF 116, EMA and chromogranin (Fig. 3C), and focally positive for cytokeratin $\mathrm{C} 11$ and NSE. They were negative with all other antibodies tested including those against adeno-hypophyseal hormones. The immunohistochemical profile of this tumor and particularly the presence of intra-cytoplasmic chromogranin-positive granules was consistent with a diagnosis of an ectopic, hormone-negative pituitary adenoma.

Plasma anterior pituitary hormones were normal and NSE was moderately elevated, whereas other tumor markers were normal (Table 2).

Long-acting octreotide treatment was well tolerated, except for moderate diarrhea that subsided promptly after the adjunction of digestive enzymes. Bleeding did not recur and nasal obstruction progressively subsided. At 3 months of therapy, a repeated endoscopic study showed a striking shrinkage of the tumor that was
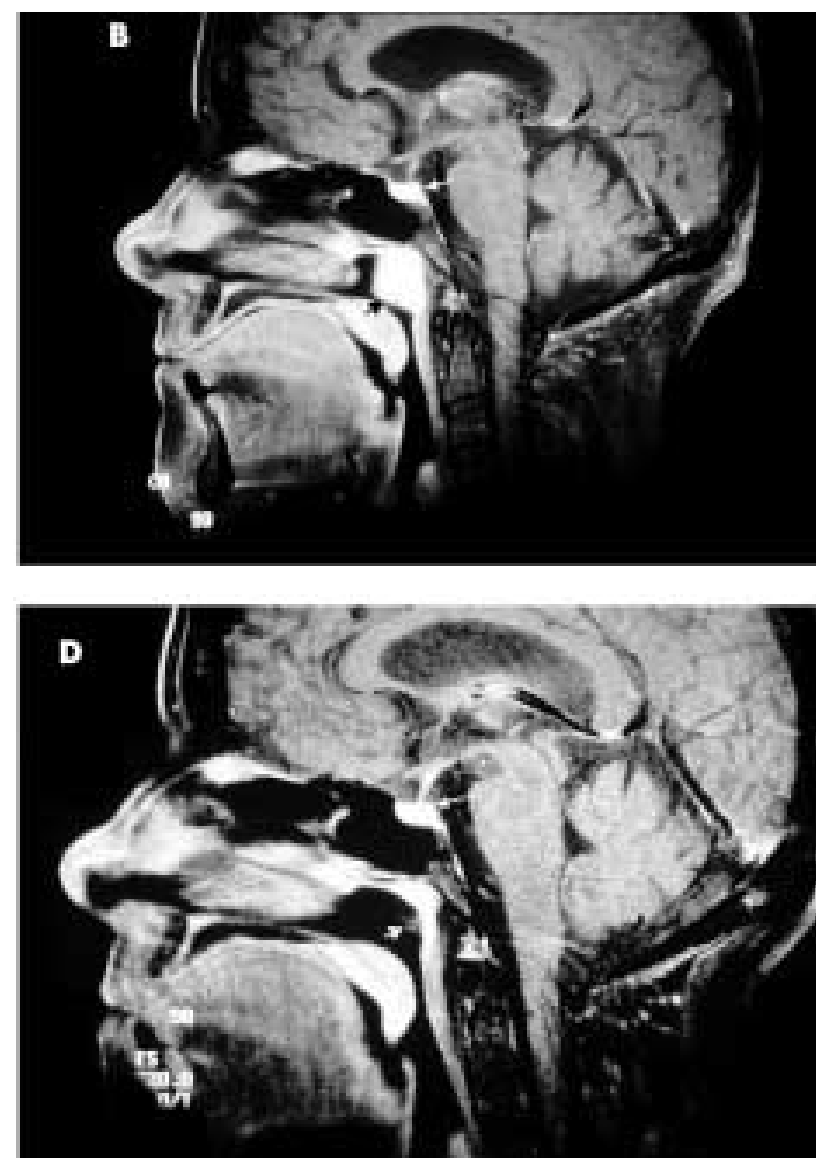


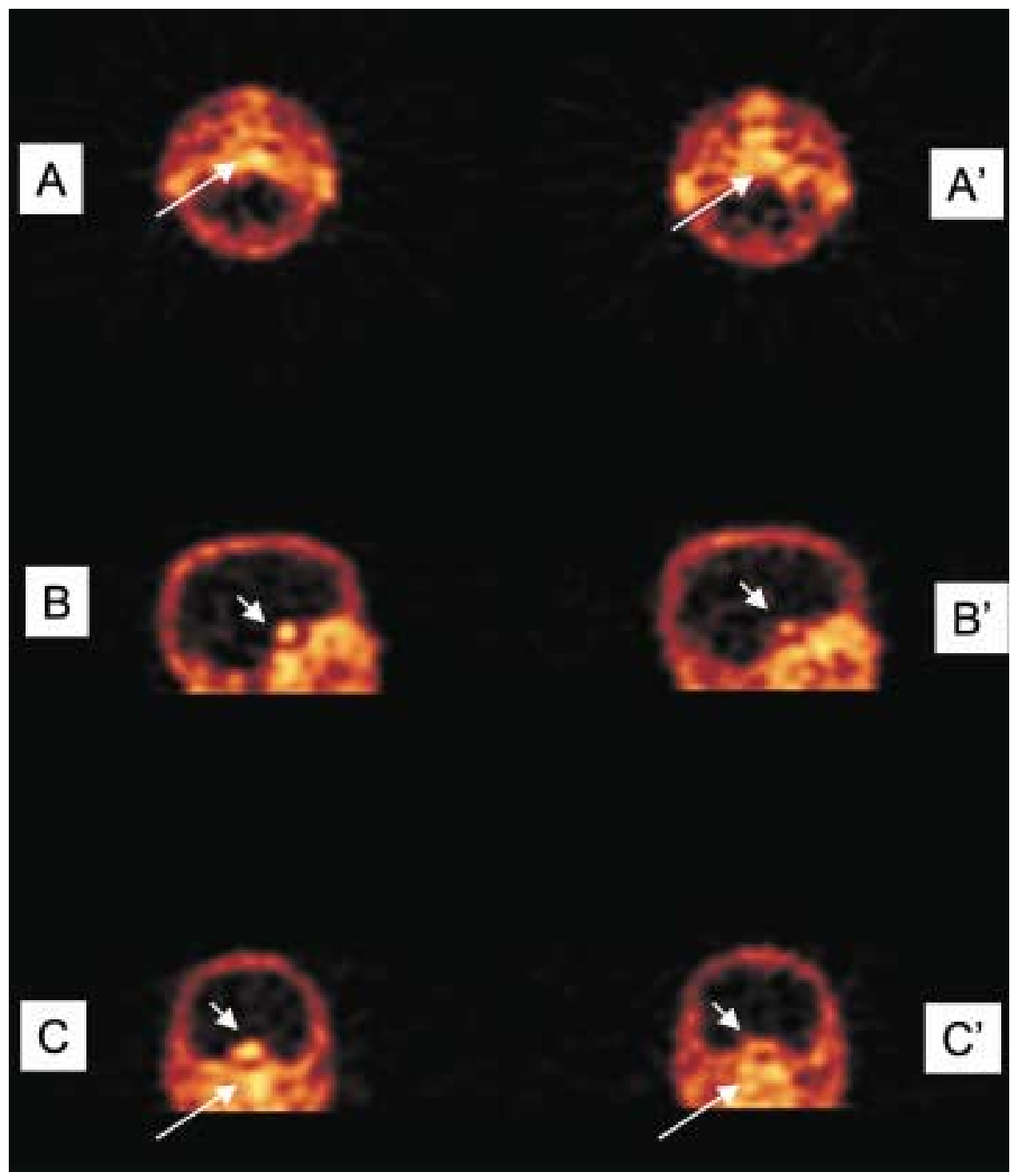

Figure 2 Transverse $\left(A\right.$ and $\left.A^{\prime}\right)$, sagittal $\left(B\right.$ and $\left.B^{\prime}\right)$ and coronal $\left(C\right.$ and $\left.C^{\prime}\right)$ images of SPECT performed $3 \mathrm{~h}$ after injection of $190 \mathrm{MBq}$ ${ }_{111}$ In-OctreoScan at diagnosis $(A-C)$ and after a 3 month long-acting octreotide treatment $\left(A^{\prime}, B^{\prime}\right.$ and $\left.C^{\prime}\right)$. A clear uptake of the tracer by the tumor was observed at diagnosis (long arrows, $\mathrm{A}$ and $\mathrm{C}$ ), and no significant activity was found in the same region after treatment (long arrows, $A^{\prime}$ and $C^{\prime}$ ). Note the similar appearance and changes of the normal pituitary, which was clearly shown only on the diagnostic sagittal and coronal views (short arrows).

confirmed on MRI, where the tumor was barely distinguishable (Fig. 1C and D). A second SRS was performed 3 months after the beginning of therapy and 4 weeks after the last i.m. injection of long-acting octreotide. SPECT images of the head demonstrated a significant decrease of the tracer uptake by the tumor and the normal pituitary when compared with the initial scan (Fig. 2A $\mathrm{A}^{\prime}, \mathrm{B}^{\prime}$ and $\mathrm{C}^{\prime}$ ). Repeated endoscopic examination, MRI and SRS, 6 months after the beginning of therapy, and repeated endoscopy at 9 months, showed similar results and the patient remains symptom-free after a year on octreotide. NSE was progressively reduced to normal and insulin-like growth factor
(IGF-I) showed a reduction of $31 \%$ but remained within the normal limits for age (Table 2).

\section{Discussion}

Ectopic pituitary tumors constitute less than $1 \%$ of all obstructive pharyngeal masses, and although they have a particularly strong tendency to bleed, they are difficult to distinguish from more common causes on clinical grounds. They arise from ectopic pituitary remnants, which persist throughout the fetal and adult life, undergoing no involution. They can be demonstrated in aged normal individuals $(9,10)$. The described cases of 


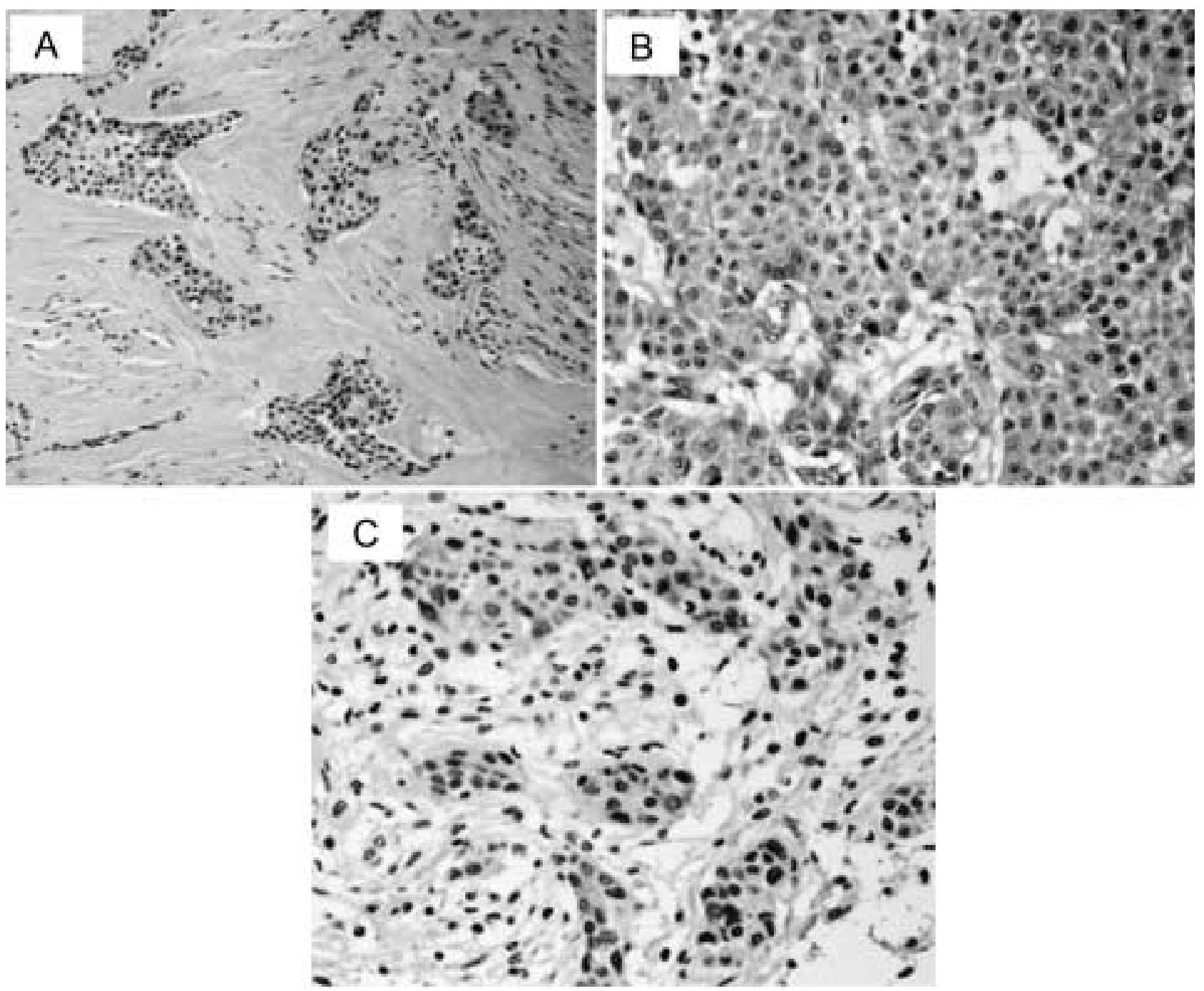

Figure 3 (A) The ectopic pituitary adenoma shows a trabecular pattern with sheets and cords separated by abundant fibrous stroma $(\mathrm{H \& E}, \times 100)$. (B) Tumor cells are cohesive, round or polygonal, have central nuclei and acidophilic cytoplasm, and show no atypia or mitoses (H\&E, $\times 200)$. (C) Immunostaining with chromogranin antibody shows intra-cytoplasmic staining in some of the tumor cells $(\times 400)$.

adenomatous transformation of those remnants have always been associated with a normal intra-sellar pituitary disclosing no anatomical continuity with the ectopic pituitary tumor (11). The neuroendocrine nature of these masses, although difficult to establish with certainty, may prove particularly favorable for the treatment, as illustrated by our case. The clinical and MRI differential diagnoses included primary rhino-pharyngeal tumor, chordoma, chondroma, chondrosarcoma, craniopharyngioma or metastatic cancer, whereas an ectopic pituitary tumor was not taken into account initially. However, the neuroendocrine nature of this tumor was underlined by the presence of intra-cytoplasmic chromogranin-positive granules in tumor cells. This was corroborated by the high somatostatin receptor content disclosed by SRS.
Ectopic pituitary adenoma should be distinguished from pituitary adenoma extending from the sella turcica by radiological examinations. This tumor must also be differentiated from olfactory neuroblastoma, which presents a fibrillary stroma and does not express keratin, unlike pituitary adenoma. Although pituitary adenoma may show some nuclear atypia, which were absent in our case, they do not have the degree of pleomorphism, mitotic activity and necrosis that characterizes small cell neuroendocrine carcinoma and sinonasal undifferentiated carcinoma.

Surgical ablation of the mass in our patient was judged potentially mutilating. Therefore, somatostatin receptor-based therapy was envisioned as an alternative to surgery. A suppressive effect of somatostatin analogs can be anticipated when the presence of somatostatin receptors (essentially subtypes SSTR2 and SSTR5) is 
Table 2 Plasma hormones and neuroendocrine tumor markers before and after octreotide treatment.

\begin{tabular}{|c|c|c|c|c|c|}
\hline & \multicolumn{4}{|c|}{ Time on octreotide } & \multirow[b]{2}{*}{ Reference interval } \\
\hline & Before & Two months & Four months & Eleven months & \\
\hline \multicolumn{6}{|l|}{ Pituitary hormones } \\
\hline $\mathrm{LH}(\mathrm{U} / \mathrm{I})$ & 49.9 & - & - & - & $20-70 \mathrm{U} / \mathrm{I}^{\star}$ \\
\hline $\mathrm{FSH}(\mathrm{U} / \mathrm{I})$ & 59 & - & - & - & $30-130 \mathrm{U} / /^{*}$ \\
\hline Free- $\alpha$ subunit (U/I) & 0.55 & - & - & - & $0.4-2.2 \mathrm{U} / \mathrm{l}$ \\
\hline PRL $(\mu \mathrm{g} / \mathrm{l})$ & 5 & - & - & - & $2-11 \mu \mathrm{g} / \mathrm{l}$ \\
\hline ACTH $(\mathrm{ng} / \mathrm{l})$ & 13 & - & - & _- & $10-60 \mathrm{ng} / \mathrm{l}$ \\
\hline Cortisol $(\mathrm{nmol} / \mathrm{l})$ & 188 & - & - & - & $60-300 \mathrm{nmol} / /{ }^{\star *}$ \\
\hline IGF-I ( $\mu \mathrm{g} / \mathrm{l})$ & 98 & - & 68 & - & $41-186 \mu \mathrm{g} / \mathrm{l}$ \\
\hline $\mathrm{TSH}(\mathrm{mU} / \mathrm{l})$ & 1.79 & - & 2.96 & - & $0.2-3.5 \mathrm{mU} / \mathrm{l}$ \\
\hline FT4 (pmol/l) & 14 & - & 12 & - & $8-22 \mathrm{pmol} / \mathrm{l}$ \\
\hline \multicolumn{6}{|l|}{ Tumor markers } \\
\hline NSE $(\mu \mathrm{g} / \mathrm{l})$ & 33.8 & 22.1 & 14.8 & 10.3 & $<12 \mu \mathrm{g} / \mathrm{l}$ \\
\hline $\mathrm{PP}(\mathrm{pmol} / \mathrm{l})$ & 47 & - & - & - & $<100 \mathrm{pmol} / \mathrm{l}$ \\
\hline GRF (pmol/l) & 47 & - & - & - & $<75 \mathrm{pmol} / \mathrm{l}$ \\
\hline GAWK (pmol/l) & 36 & - & - & - & $<80 \mathrm{pmol} / \mathrm{l}$ \\
\hline
\end{tabular}

* Postmenopausal values.

** p.m. values.

$\mathrm{FSH}=$ follicle-stimulating hormone; $\mathrm{PP}=$ pancreatic polypeptide; GRF = growth hormone-releasing factor; GAWK = GAWK, a sequence of chromogranin $\mathrm{B} ; \mathrm{FT} 4$ = free thyroxine.

shown in a tumor mass (12). Although we did not measure in vitro receptors in a tissue specimen, we assumed they were abundant in the tumor according to the results of SRS, and indeed, somatostatin analog treatment resulted in an impressive tumor mass reduction together with normalization of NSE, the unique tumor marker observed in this case. This is consistent with the well-known effects of somatostatin analogs on pituitary GH-secreting adenomas and on gastro-entero-pancreatic neuroendocrine tumors (13-15). It should be noted that treatment with somatostatin analogs usually does not result in an anti-tumoral effect on non-functioning intra-sellar pituitary adenomas (16), contrary to the non-functioning pharyngeal pituitary adenoma discussed here.

In conclusion, to the best of our knowledge this is the first case of a pharyngeal pituitary adenoma in which a high somatostatin receptor content was demonstrated by SRS and which was successfully treated with a somatostatin analog, thus avoiding surgery. However, the duration of the ongoing anti-tumoral effect cannot be predicted, and the question remains open whether long-term octreotide therapy would modify the operability, should tumor regrowth occur.

\section{References}

1 Hori A, Schmidt D \& Rickels E. Pharyngeal pituitary: development, malformation and tumorigenesis. Acta Neuropathologica $199998262-272$

2 Fuller GN \& Batsakis JG. Pharyngeal hypophysis. Annals of Otology, Rhinology and Laryngology $1996 \mathbf{1 0 5} 671-672$.

3 Erdheim J. Uber einen Hypophysentumor von ungewöhnlichem Sitz. Beitrage zur Pathologischen Anatomie und zur Allgemeinen Pathologie 190946 233-240.
4 Asa SL, Kowacs K, Horvath E, Losinski NE, Laszlo FA, Domokos I et al. Human fetal adenohypophysis. Electron microscopic and ultrastructural immunocytochemical analysis. Neuroendocrinology 198848 423-431.

5 McPhie JL \& Beck JS. The histological features of the pharyngeal pituitary gland in normal and endocrinologically disturbed patients. Clinical Endocrinology 19732 157-173.

6 Kollias SS, Ball WS \& Prenger EC. Review of embryologic development of the pituitary gland and report of a case of hypophyseal duplication detected by MRI. Neuroradiology 199537 3-12.

7 Barry A. Warner DO, Santen RJ \& Page RB. Growth hormone and prolactin secretion by a tumor of the pharyngeal pituitary. Annals of Internal Medicine 198296 65-66.

8 Hou L, Harsbarger T, Herrick MK \& Tse V. Suprasellar adrenocorticotropic hormone-secreting ectopic pituitary adenoma: case report and literature review. Neurosurgery $200250618-625$

9 Hori A, Schmidt D \& Kuebber S. Immunohistochemical survey of migration of human anterior pituitary cells in developmental, pathological and clinical aspects: a review. Microscopy Research and Technology $1999 \mathbf{4 6} 59-68$.

10 Ciocca DR, Libertad AP, Puy LA \& Stati AO. Identification of seven hormone-producing cell types in the human pharyngeal hypophysis. Journal of Clinical Endocrinology and Metabolism 198560 $212-216$.

11 Lloyd RV, Chandler WF, Kovacs K, Sci D \& Ryan N. Ectopic pituitary adenoma with normal anterior pituitary gland. American Journal of Surgical Pathology 199610 546-552.

12 Saveanu A, Morange-Ramos I, Gunz G, Dufour H, Enjalbert A \& Jaquet P. A luteinizing hormone-, alpha-subunit- and prolactinsecreting pituitary adenoma responsive to somatostatin analogs: in vivo and in vitro studies. European Journal of Endocrinology $200114535-41$.

13 Wasko R, Ruchala M, Sawicka J, Kotwicka M, Liebert W \& Sowinski J. Short term pre-surgical treatment with somatostatin analogues, octreotide and lanreotide, in acromegaly. Journal of Endocrinological Investigation 200023 12-18.

14 Raderer M, Kurtara A, Scheithauer W, Fiebiger W, Weinlaender G \& Oberhuber G. Different response to the long acting somatostatin analogues lanreotide and octreotide in a patient with a malignant carcinoid. Oncology $200160141-145$. 
15 Aparicio T, Ducreux M, Baudin E, Sabourin JC, DeBaere T, Mitry E et al. Antitumor activity of somatostatin analogues in progressive metastatic neuroendocrine tumours. European Journal of Cancer 200137 1014-1019.

16 Merola B, Colao A, Ferone D, Selleri A, Di Sarno A, Marzullo P et al. Effects of chronic treatment with octreotide in patients with functionless pituitary adenoma. Hormone Research 199340 149-155.

17 Tovi F, Hirsch M, Sacks M \& Leiberman A. Ectopic pituitary adenoma of the sphenoidal sinus: report of a case and review of the literature. Head and Neck 199012 264-268.

18 Borit A \& Blanchard TP. Sphenoidal pituitary adenoma. Human Pathology 197910 93-96.

19 Burch WM, Kramer RS, Kenan PD \& Hammon CB. Cushing's disease caused by an ectopic pituitary adenoma within the sphenoid sinus. New England Journal of Medicine 1985312 587-588.

20 Siegert B, Von Mühlen A \& Brabant G. Ectopic non-functioning pituitary adenoma in the sphenoid sinus. Journal of Clinical Endocrinology and Metabolism 199681 430-431.

21 Matsushita H, Matsuya S, Endo Y, Hara M, Shishiba Y, Yamaguchi $\mathrm{H}$ et al. A prolactin producing tumor originated in the sphenoid sinus. Acta Pathologica Japonica 198434 103-109.

22 Horiuchi T, Tanaka Y, Kobayashi S, Unoki T \& Yokoh A. Rapidly growing ectopic pituitary adenoma within the sphenoid sinus. Neurologia Medico-Chirurgica 199737 399-402.

23 Kikuchi K, Kowada M, Sasaki J \& Sageshima M. Large pituitary adenoma of the sphenoid sinus and rhinopaharynx: report of a case with ultrastructural evaluation. Surgical Neurology 1994 42 330-334.

24 Heitzmann A, Jan M, Lecomte P, Ruchoux MM, Lhuintre Y \& Tillet Y. Ectopic prolactinoma within the sphenoidal sinus. Neurosurgery $198924279-282$.

25 Schleingart DE, Chandler WF, Lloyd RV \& Ibarra-Perez G. Cushing's syndrome caused by an ectopic pituitary adenoma. Neurosurgery 198721 223-227.

26 Hattori N, Ishihara T, Saiwai S, Moridera K, Hino M, Ikekubo K et al. Ectopic prolactinoma on MRI. Journal of Computer Assisted Tomography 199418 936-938.

27 Moriwaki T, Tadokoro M, Hoshikawa S, Takenchi E, Abe M \& Shinagawa T. A case report of pituitary adenoma of the sphenoid sinus diagnosed only by fine-needle aspiration cytology. Journal of the Japanese Society for Clinical Cytology 199332 435-442.

28 Slonim SM, Haykal HA, Cushing GW, Freidberg SR \& Lee AK. MRI appearances of an ectopic pituitary adenoma: case report and review of the literature. Neuroradiology 199335 546-548.

29 Tsuboi M, Adachi H, Miyoshi Y \& Aoi M. A case of ectopic pituitary adenoma localized in the sphenoid sinus. No Shinkei Geka 199927 1007-1011.

30 Horiuchi T, Tanaka Y, Kobayashi S, Unoki T \& Yokoh A. Rapidlygrowing ectopic pituitary adenoma within the sphenoid sinus: case report. Neurologica Medico-Chirurgica 199737 399-402.

31 Kohno M, Sasaki T, Narita Y, Teramoto A \& Takakura K. Suprasellar ectopic pituitary adenoma: case report. Neurologica Medico-Chirurgica 199434 538-542.

32 Cushing H. The chiasmal syndrome. Archives of Ophthalmology $19303505-551$.

33 Luk KH, Lam KS, Kung AW, Fung CF \& Leung SY. Suprasellar ectopic pituitary adenoma as cranial diabetes insipidus. Postgraduate Medical Journal 199268 467-469.

34 Lindboe CF, Unsgard G, Myhr G \& Scott H. ACTH and TSH producing ectopic suprasellar pituitary adenoma of the hypothalamic region: case report. Clinical Neuropathology $199312138-141$.

35 Kepes JJ \& Fritzlent TJ. Large invasive chromophobe adenoma with well preserved pituitary gland. Neurology $196414537-541$.

36 Ogilvy KM \& Jakuboski J. Intracranial dissemination of pituitary adenoma. Journal of Neurology, Neurosurgery and Psychiatry 19733 199-205.

37 Rothman LH, Sher J, Queneer RN \& Tenner MS. Intracranial ectopic adenoma. Journal of Neurosurgery $1976 \mathbf{4 4}$ 96-99.
38 Iwai Y, Hakuba A, Katsuyama J, Nagata Y, Nishimura S, Abe K et al. A case of ectopic large pituitary adenoma. No Shinkei Geka $19901871-75$.

39 Matsumura A, Meguro K, Tsurushima H, Tomono Y \& Doi M. Suprasellar ectopic pituitary adenoma: case report and review of the literature. Neurosurgery $1990 \mathbf{2 6} 681-685$.

40 Hamada J, Seto H, Miura M, Kuratsu J \& Ushio Y. Suprasellar pituitary adenoma arising from the pars tuberalis: case report. Neurosurgery 199027 647-649.

41 Tamaki N, Shirakuni T, Kokunai T, Matsumoto S, Fujimori T \& Maeda S. Ectopic pituitary adenoma in the suprasellar cistern. Surgical Neurology $199135389-394$.

42 Neilson K \& Chadarevian JP. Ectopic anterior pituitary corticotropic tumor in a six-year-old boy. Histological, ultrastructural and immunocytochemical study. Virchows Archiv $1987 \mathbf{4 1 1}$ 267-273.

43 Dyer EH, Civit T, Abecassis JP \& Derome PJ. Functioning ectopic supradiaphragmatic pituitary adenomas. Neurosurgery 199434 529-532.

44 Goel A, Satoskar AR, Nagpal RD \& Desai AP. Intracranial ectopic pituitary tumor. British Journal of Neurosurgery 19904 339-342.

45 Jung S, Kim JH, Kim TS, Lee MC, Seo JJ, Park JW et al. Supradiaphragmatic ectopic adrenocorticotropic hormone-secreting adenoma. Pathology International 200050 901-904.

46 Chessin H, Urdaneta N, Smith H \& Gilder JV. Chromophobe adenoma manifesting as a nasopharyngeal mass. Archives of Otolaryngology $1976 \mathbf{1 0 2} 631-633$.

47 Langford L \& Batsakis JG. Pituitary gland involvement of the sinonasal tract. Annals of Otology, Rhinology and Laryngology 199510 $167-169$.

48 Kitajiri S, Hosaka N, Tabuchi K, Hiraumi H, Nogaki H, Tatsumi S et al. A case report of FSH-producing nasal ectopic pituitary adenoma extending to the frontal cranial fossa. Archives of Otolaryngology, Head and Neck Surgery $2000126782-784$.

49 Li J, Wang L \& Guo J. Primary nasal adenoma: a case report. Chinese Medical Journal $1997110731-733$.

50 Tal A. Cushing's disease caused by ectopic pituitary adenoma within the pituitary stalk. Southern Medical Journal $1993 \mathbf{8 6}$ 249-250.

51 Corenblum B, LeBlanc FE \& Watanabe M. Acromegaly with an adenomatous pharyngeal pituitary. Journal of the American Medical Association $1980 \mathbf{2 4 3} 1456-1457$.

52 Warner BA, Santen RJ \& Page RB. Growth hormone and prolactin secretion by a tumor of a pharyngeal pituitary. Annals of Internal Medicine 198296 65-66.

53 Kopf PO, Kopf R \& Nickol HJ. Heterotopes pharyngeales Hypophysenadenom. HNO $19833128-30$.

54 Lee WY, Oh KW, Yoon KH, Kang MI, Cha BY, Lee KW et al. Cushing's disease due to an ACTH secreting pharyngeal pituitary tumor. European Journal of Endocrinology 2001 144 181-182.

55 Kleinschmidt-DeMaster BK, Winston KR, Rubinstein D \& Samuels $\mathrm{MH}$. Ectopic pituitary adenoma of the third ventricle: case report. Journal of Neurosurgery 199072 139-142.

56 Shankar SK, Tandon PN \& Roy S. Ventricular chromophobe adenoma with normal adenohypophysis. Acta Neuropathologica $197635353-356$.

57 Ohnishi T, Arita N, Yoshimine T \& Mori S. Intracavernous sinus ectopic adrenocorticotropin-secreting tumours causing therapeutic failure in transsphenoidal surgery for Cushing's disease. Acta Neurochirurgica $2000142855-864$.

58 Akimoto J, Nagura M \& Onodera Y. Cystic ectopic pituitary non secreting adenoma: report of a case. Brain and Nerve $1994 \mathbf{4 7}$ 1092-1097.

59 De Witte O, Massager N, Salmon I, Meyer S, Dooms G \& Brotchi J. Ectopic prolactinoma in the clivus. Acta Chirurgica 199598 $10-13$.

60 Wong K, Raisanen J, Taylor SL, McDermott MW, Wilson CB \& Gutin PH. Pituitary adenoma as an unsuspected clival tumor. American Journal of Surgical Pathology 199519 900-903. 
61 Wilson CB, Mindermann T \& Tyrell JB. Intracavernous sinus adrenocorticotropic adenoma causing Cushing's disease. Journal of Clinical Endocrinology and Metabolism 199580 1774-1777.

62 Sanno N, Tahara S, Yoshida Y, Onose H, Wakabayashi I \& Teramoto A. Ectopic corticotroph-adenoma in the cavernous sinus: case report. Neurosurgery $1999 \mathbf{4 5} 914-918$.

63 Migliore A, Calzolari F, Marzola A, Ghadirpour R \& Migliore MM. Intrinsic third ventricle craniopharyngioma. Child's Nervous System 19928 56-58.

64 Lewin R, Ruffolo E \& Saraceno C. Craniopharyngioma arising in the pharyngeal hypophysis. Southern Medical Journal 198477 1519-1523.
65 Graziani N, Donnet A, N’jee Bugha T, Dufour H, Figarella-Branger D \& Grisoli F. Ectopic basisphenoidal craniopharyngioma: case report and review of the literature. Neurosurgery 199434 346-349.

66 Podoshin L, Rohan L, Alman MM \& Peyser E. Pharyngeal craniopharyngioma. Journal of Laryngology and Otology $1975 \mathbf{8 9}$ 445-452.

Received 25 October 2002

Accepted 4 December 2002 